\title{
Article \\ Fabrication of AuNPs/MWCNTS/Chitosan Nanocomposite for the Electrochemical Aptasensing of Cadmium in Water
}

\author{
Selma Rabai ${ }^{1}$, Ahlem Teniou ${ }^{2}\left(\mathbb{D}\right.$, Gaëlle Catanante $\left.{ }^{3}{ }^{(}\right)$, Messaoud Benounis ${ }^{1}$, Jean-Louis Marty ${ }^{2}$ and \\ Amina Rhouati ${ }^{2, *}$ \\ 1 Laboratory of Sensors, Instrumentations and Process (LCIP), University of Khenchela, Khenchela 40000, \\ Algeria; gp.selma@yahoo.fr (S.R.); benounis@yahoo.fr (M.B.) \\ 2 Bioengineering Laboratory, Higher National School of Biotechnology, Constantine 25100, Algeria; \\ teniouahlem97@gmail.com (A.T.); jlmarty@univ-perp.fr (J.-L.M.) \\ 3 Laboratoire Biocapteurs, Analyse et Environnement (BAE), Université de Perpignan Via Domitia, \\ 66860 Perpignan, France; gaelle.catanante@univ-perp.fr \\ * Correspondence: amina.rhouati@gmail.com
}

\section{check for}

updates

Citation: Rabai, S.; Teniou, A.; Catanante, G.; Benounis, M.; Marty, J.-L.; Rhouati, A. Fabrication of AuNPs/MWCNTS/Chitosan Nanocomposite for the Electrochemical Aptasensing of Cadmium in Water. Sensors 2022, 22, 105. https://doi.org/10.3390/ s22010105

Academic Editors: Alisa Rudnitskaya and Matjaž Finšgar

Received: 20 October 2021

Accepted: 20 December 2021

Published: 24 December 2021

Publisher's Note: MDPI stays neutral with regard to jurisdictional claims in published maps and institutional affiliations.

Copyright: (C) 2021 by the authors. Licensee MDPI, Basel, Switzerland. This article is an open access article distributed under the terms and conditions of the Creative Commons Attribution (CC BY) license (https:// creativecommons.org/licenses/by/ $4.0 /)$.

\begin{abstract}
Cadmium $\left(\mathrm{Cd}^{2+}\right)$ is one of the most toxic heavy metals causing serious health problems; thus, designing accurate analytical methods for monitoring such pollutants is highly urgent. Herein, we report a label-free electrochemical aptasensor for cadmium detection in water. For this, a nanocomposite combining the advantages of gold nanoparticles (AuNPs), carbon nanotubes (CNTs) and chitosan (Cs) was constructed and used as immobilization support for the cadmium aptamer. First, the surface of a glassy carbon electrode (GCE) was modified with CNTs-CS. Then, AuNPs were deposited on CNTs-CS/GCE using chrono-amperometry. Finally, the immobilization of the amino-modified Cd-aptamer was achieved via glutaraldehyde cross-linking. The different synthesis steps of the AuNPs/CNTs/CS nano assembly were characterized by cyclic voltammetry (CV). Electrochemical impedance spectroscopy (EIS) was employed for cadmium determination. The proposed biosensor exhibited excellent performances for cadmium detection at a low applied potential $(-0.5 \mathrm{~V})$ with a high sensitivity $\left(1.2 \mathrm{~K} \Omega \cdot \mathrm{M}^{-1}\right)$, a detection limit of $0.02 \mathrm{pM}$ and a wide linear range $\left(10^{-13}-10^{-4} \mathrm{M}\right)$. Moreover, the aptasensor showed a good selectivity against the interfering ions: $\mathrm{Pb}^{2+} ; \mathrm{Hg}^{2+}$ and $\mathrm{Zn}^{2+}$. Our electrochemical biosensor provides a simple and sensitive approach for $\mathrm{Cd}^{2+}$ detection in aqueous solutions, with promising applications in the monitoring of trace amounts of heavy metals in real samples.
\end{abstract}

Keywords: cadmium; aptasensor; electrochemical; environment; pollutant

\section{Introduction}

Aptamers are short oligonucleotidic sequences identified by an in vitro process called SELEX, the "Systematic Evolution of ligands by Exponential enrichment" [1]. They are generated by a simple chemical synthesis with extreme precision and reproducibility [2]. Aptamers are characterized by a high specificity, selectivity and stability, making them strong competitors of antibodies in molecular analysis [3,4].They thus constitute good candidates as effective probes for biosensing [5-7]. One of the key challenges in the application of aptamers in analysis is to ensure an efficient and cost-effective immobilization method. In order to immobilize aptamers in a functional manner, the conjugation process must not interfere with aptamer folding [8]. As they are chemically synthesized, aptamers can be easily labeled to incorporate functional groups in $3^{\prime}$ or $5^{\prime}$ end. Different modifications can be used, such as thiol groups, to allow immobilization on gold electrodes and carboxylic or amine groups for carbon electrodes. Among the different strategies, the immobilization of aptamers onto nanomaterials and nanostructured materials has gained much attention in recent years.

Nanotechnology is playing an increasingly important role in different fields, including sensing and biosensing $[9,10]$. The use of nanomaterials is advantageous; whether 
for sensors miniaturization, signal amplification or for developing new immobilization strategies for biomolecules [11,12]. Among the wide range of nanomaterials, carbon and metallic nanostructures have attracted particular attention. Carbon nanomaterials, such as carbon nanotubes (CNTs) and nanofibers, graphene and nano diamond, are characterized with excellent analytical and electroanalytical properties. CNTs are particularly interesting in electrochemical sensing because of their remarkable electrical conductivity. Their length/diameter aspect ratio provides a high surface/volume ratio. Indeed, CNTs have a unique ability to promote fast electron transfer kinetics for a wide range of electroactive species $[13,14]$. CNTs-modified electrodes have been widely used as promising anchors for bioreceptors (enzymes, proteins, nucleic acids, etc.) because of their biocompatibility, sensitivity and improved signal to noise ratio [15]. In parallel, carbon nanotubes can be easily functionalized by other nanomaterials, chemical groups or covered with different polymers. In recent years, CNTs decorated with metallic nanoparticles demonstrated a great potential in the development of sensing platforms. Owing to their unique properties, gold nanoparticles (AuNPs) have been widely integrated in CNTs-based nanohybrids [16-18]. AuNPs are characterized with a high electrochemical potential range, improving electron transfer and contributing tothe increased sensitivity of biosensors. They provide a minimized diffusion problem with an increased contact surface and graft density of biomolecules. In addition, they maintain the stability and biological activity of biomolecules [19,20]. The synergistic contributions of carbon nanotubes and gold nanoparticles have been widely explored in chemical sensing strategies $[17,21]$. Some reports explored AuNPs-CNTs nanohybrids as immobilization support for enzymatic bioreceptors [22,23]. However, just one report describes the combined application of AuNPs and CNTs in aptasensing [24].

In this work, we aim to investigate the advantages of CNTs and AuNPs in the immobilization of an amino-modified aptamer. The adopted procedure is based on the modification of a glassy carbon electrode (GCE) with dispersed carbon nanotubes in Chitosan (CS). Once grafted around carbon nanotubes, chitosan improves their solubility and biocompatibility [25]. Then, gold nanoparticles were electro grafted on CNTs-CS/GCE by using chrono-amperometry. The synergistic effect of CNTs and Au-NPs will make the electron transfer easier with a good conductivity and high electroactive surface area, thus providing a biocompatible microenvironment for the aptamer. Afterwards, the biorecognition element was immobilized by cross-linking the amino-modified aptamer and CS through glutaraldehyde onto the AuNPs/CNTs/CS modified surface $[25,26]$. The different steps of the aptasensing platform fabrication were characterized electrochemically by cyclic voltammetry (CV).

In order to evaluate the analytical performance of the functionalized surface, cadmium ions $\left(\mathrm{Cd}^{2+}\right)$ were selected as a target analyte. Cadmium is a toxic heavy metal affecting lungs, kidneys, bones and the immune system. The toxicity of cadmium occurs by an oral or respiratory route [27]. It can lead to lung and prostate cancer, cause cardiovascular diseases and anemia, as it seems to contribute to autoimmune thyroid diseases. Because of this, the World Health Organization has designated cadmium as a human carcinogen which can lead to death [28]. In the literature, few reports describe the electrochemical aptasensing of this hazardous heavy metal. In a previous study, we developed a biosensing platform, where diazonium chemistry was used for immobilizing cadmium aptamer [29]. In this work, a new immobilization strategy was adopted by exploring the unique properties of AuNPs and carbon nanotubes. Electrochemical impedance spectroscopy (EIS) was used to measure the extent of binding between cadmium and its specific aptamer immobilized on the AuNPs/CNTs/CS/GCE surface. First, the constructed biosensing platform was used to detect cadmium in phosphate-buffered saline, where excellent analytical performances have been obtained. We reached the low detection limit of $0.02 \mathrm{pM}$ and a wide linear range, varying from $10^{-3} \mathrm{M}$ to $10^{-13} \mathrm{M}$. The biosensor selectivity for cadmium detection was also investigated against a number of competing metal ions, including lead, mercury and zinc. Finally, the applicability of the label-free aptasensor has been demonstrated in real water samples. 


\section{Experimental}

\subsection{Chemical and Reagents}

Cadmium (II) nitrate $\left(\mathrm{Cd}\left(\mathrm{NO}_{3}\right)_{2}\right)$, tetra chloroauric acid $\left(\mathrm{HAuCl}_{4}\right)$, glutaraldehyde $(25 \%)$, chitosan (deacetylation $\geq 75 \%$ ), phosphate buffered saline (PBS), potassium ferrocyanide (II), potassium ferricyanide (III), and sodium sulfate $\left(\mathrm{Na}_{2} \mathrm{SO}_{4}\right)$, were purchased from Sigma-Aldrich, France. Carbon nanotubes (CNTs) were obtained from Sigma-Aldrich, France, and were functionalized with carboxyl groups $(\mathrm{COOH})$. Cadmium aptamer was synthesized and purchased from Microsynth, Switzerland. The specific sequence of the aptamer was as follows:

Aptamer sequence (5'amino-modified): $5^{\prime}$-ACC GAC CGT GCT GGA CTC TGG ACT GTT GTG GTA TTA TTT TTG GTT GTG CAG TAT GAG CGA GCG TTG CG-3’ [30].

\subsection{Instrumentation}

The electrochemical experiments were carried out using a potentiostat (Biologic ECLab SP-300, Seyssinet-Pariset, France). All experiments were performed at room temperature. The modeling of the obtained EIS data was achieved by the EC-Lab software using the Randomize + Simplex method. Herein, randomizing was stopped on 100,000 iterations and the fit stopped on 5000 iterations. Electrochemical experiments were carried out using a conventional three-electrodes system with a GCE $(\mathrm{U}=3 \mathrm{~mm})$ as the working electrode, a platinum wire as the auxiliary electrode, and an $\mathrm{Ag} / \mathrm{AgCl} / 3.0 \mathrm{M} \mathrm{KCl}$ as the reference electrode. Aptamer heating was performed using a thermocycler from Eppendorf.

\subsection{Fabrication of the Aptasensor}

Figure 1 illustrates the different steps of fabrication of the aptamer/CNTs/AuNPs modified GCE surface. First, GCE was modified by a drop of $6 \mu \mathrm{L}$ of $0.5 \mathrm{mg} \mathrm{mL}^{-1} \mathrm{CNTs}-$ CS (1 mg of CNTs dispersed in $2.0 \mathrm{~mL}$ of $0.2 \%$ CS solution) and kept to dry in air. Then, AuNPs were electrodeposited on a CNTs-CS modified electrode with potentiostatic electrodeposition of $0.2 \mathrm{M} \mathrm{Na}_{2} \mathrm{SO}_{4}$ solution containing $1 \mathrm{mM}$ of $\mathrm{HAuCl}_{4}$ for $400 \mathrm{~s}$ at $-0.2 \mathrm{~V}$. After the electrodeposition of NPs, the modified electrode was gently rinsed in water and air-dried at room temperature. For aptamer immobilization, $6 \mu \mathrm{L}$ of CS solution $(0.2 \%)$ were added to the AuNPs/CNTs/CS film and air-dried at room temperature. Then the modified electrode was immersed in a $0.25 \%$ glutaraldehyde solution for $2 \mathrm{~h}$ followed by the surface incubation with $5 \mu \mathrm{L}$ of aptamer solution overnight at $4{ }^{\circ} \mathrm{C}$. Some pictures of the real sensor and steps of fabrications are provided in the Supplementary Materials.

\subsection{FTIR Characterization}

To further confirm the immobilization of AuNPs on the MWCNT/Chitosan, a FT-IR spectrometer (Shimadzu, Noisiel, France) equipped with a crystal ATR single reflection diamond-sampling module was used. Infrared spectra were collected at an average of five scans per sample between the wave number range of $4000-500 \mathrm{~cm}^{-1}$ at a resolution of $4 \mathrm{~cm}^{-1}$, and LabSolutions IR Software was used to analyze spectra. The analysis was kept simple, since at first the spectrum of a bare substrate was recorded and considered as a reference. In the second step, the spectrum of substrates having MWCNTs and AuNPs-decorated MWCNT films were recorded and, finally, the spectrum of an aptamerfunctionalized, AuNPs/MWCNT film was recorded.

\subsection{Analytical Performance of the Label-Free Aptasensor}

Once the aptamer immobilized on the electrode surface, the resulting aptasensor was tested for cadmium detection. For this, the modified surface was incubated with increasing concentrations of cadmium prepared in PBS buffer for $30 \mathrm{~min}$. Then, the electrochemical response was monitored by EIS. In parallel, the aptasensor selectivity was studied by incubating the sensing surface with different concentrations of other interfering heavy metals, $\mathrm{Hg}^{2+}, \mathrm{Pb}^{2+}$ and $\mathrm{Zn}^{2+}$, over 30 min. 

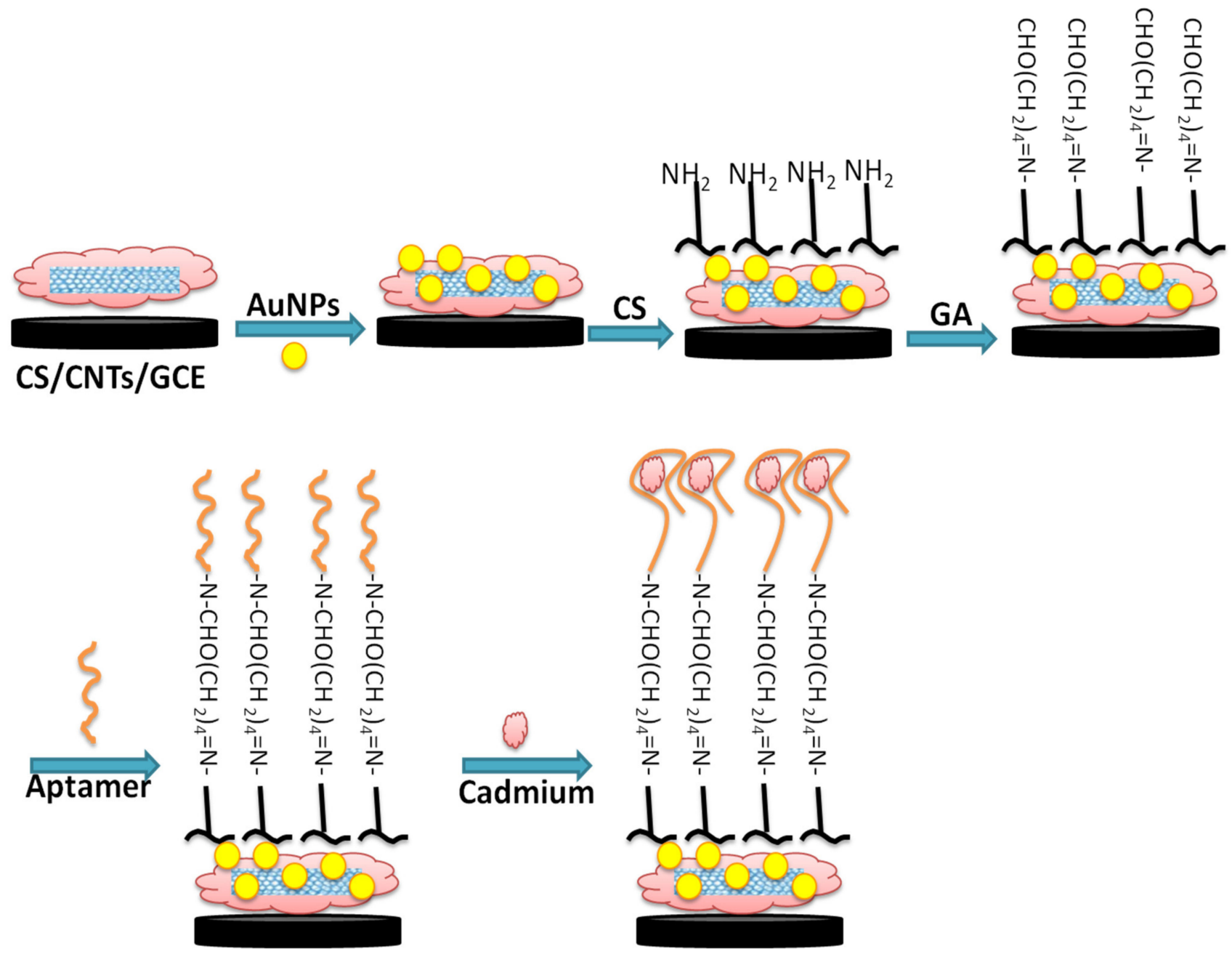

Figure 1. Schematic illustration of GCE chemical surface modification with CNTs-AuNPs/CS nanocomposite for aptamer immobilization and application in cadmium detection.

\subsection{Real Sample Analysis}

In order to validate and evaluate the accuracy and applicability of our aptasensor, analyses were carried out on real river water polluted by public work wastes and containing nitrate and cadmium [31]. This river is crossed by a volcanic water source from the Hammam Essalihine valley (Khenchela, Algeria) which is rich in minerals, such as bicarbonates, sulphates, calcium and magnesium. We have obtained samples from the river containing cadmium and other potential interferences.

\section{Results and Discussion}

\subsection{FT-IR Characterization of the Fabrication Steps}

FTIR analysis were performed to study the different steps of the aptasensor fabrication. Figure 2 shows the FTIR spectra of the activated CNTs (curve a), activated CNTs-AuNPs (curve b), and activated CNTs-AuNPs-Aptamer (curve c). As shown in Figure 2, The FTIR spectrum of activated CNTs (curve a) presents a characteristic carboxyl peak at $1716.64 \mathrm{~cm}^{-1}$ which can be attributed to $\mathrm{C}=\mathrm{O}$ stretching. Therefore, we can conclude that the CNTs have been successfully activated by introducing the carboxylic group. Moreover, the vibration peak at $1558.48 \mathrm{~cm}^{-1}$ confirms the presence of C-C double bond that forms the framework of the carbon nanotube sidewall [32,33]. A strong peak was also observed at $1066.63 \mathrm{~cm}^{-1}$; this is probably associated to the stretching of sulfoxide bond (S-O), usually created in defective CNT areas. As was reported by Chiang's group, a high $\mathrm{H}_{2} \mathrm{SO}_{4}$ concentration may lead to the remaining of sulfoxide groups between two free carbons 
at the end, defect carbons or two different MWCNTs [34]. On the other hand, the strong (large) band observed between $2900-3500 \mathrm{~cm}^{-1}$ can be attributed to the $\mathrm{O}-\mathrm{H}$ stretching mode of the carboxyl groups. However, the sharp peak at $1406 \mathrm{~cm}^{-1}$ may be related to the nitro group formed during high-pressure $\mathrm{HNO}_{3}$ treatment under heating conditions [35]. After the electrodeposition of AuNPs, FTIR spectra was also recorded in curve b in Figure 2. As compared to the spectra shown in curve (a), the strong band between $2900-3500 \mathrm{~cm}^{-1}$ related to the $\mathrm{O}-\mathrm{H}$ group was weakened and shifted $\left(2800-2250 \mathrm{~cm}^{-1}\right)$. This can be related to the attachment of AuNPs to the surface of CNTs [36]. Based on thesmall shoulder observed in the range of 500 to $750 \mathrm{~cm}^{-1}$, the covalent attachment of AuNPs could be confirmed, and thiscan be assigned to stretch the mode of $\mathrm{C}-\mathrm{S}$ groups [37]. Finally, the last step of the aptasensor fabrication corresponding to the aptamer immobilization onto the MWCNTs-AuNPs composite was also explored by FTIR analysis. The obtained spectra in curve $\mathrm{c}$ in Figure 2 shows additional bands at $1558 \mathrm{~cm}^{-1}$, confirming the aptamer binding.

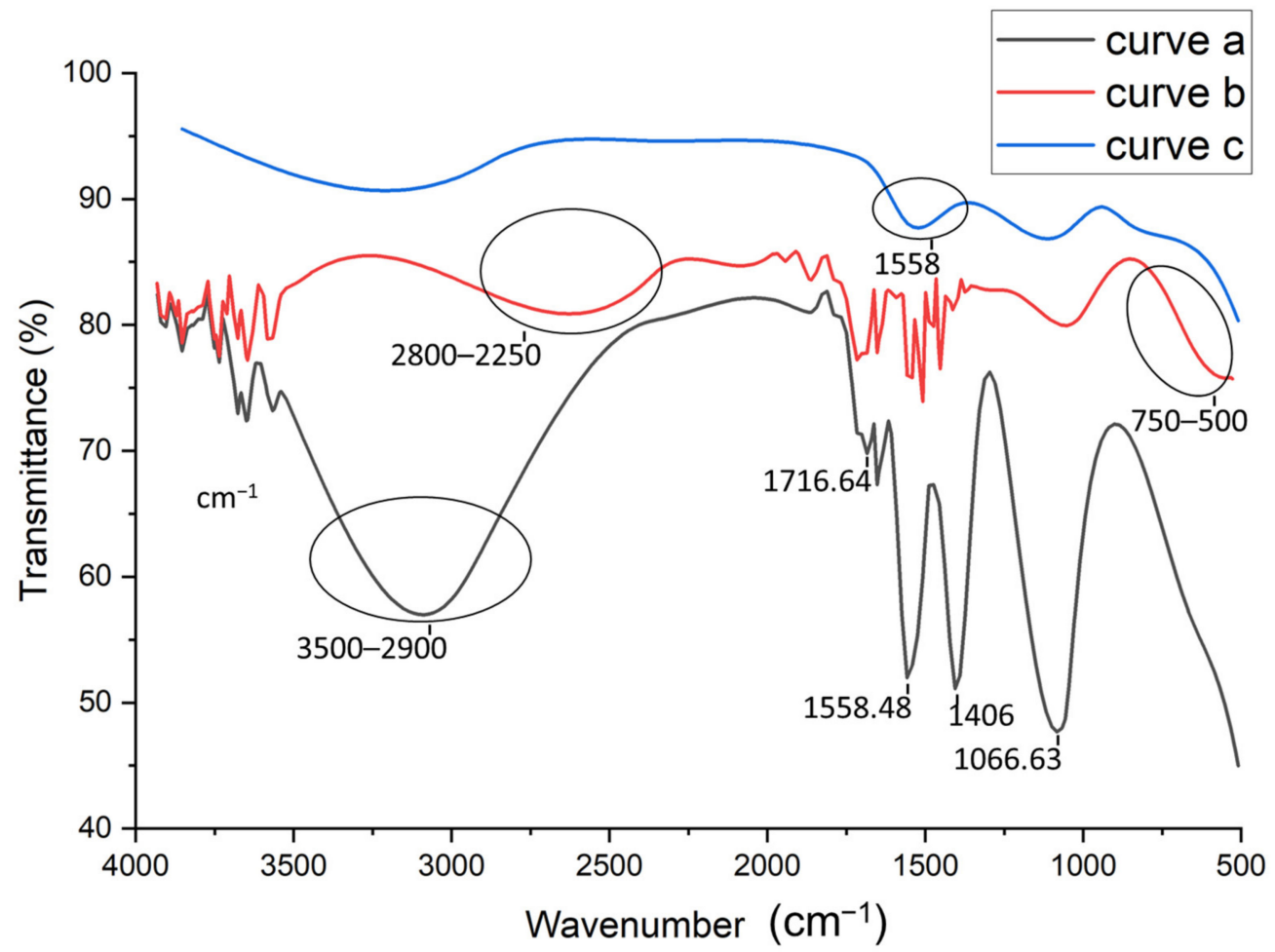

Figure 2. FTIR spectra for: activated carbon nanotubes (CNTs) (curve a), Gold nanoparticles (AuNPs)/CNTs (curve b), Aptamer/AuNPs/CNTS (curve c).

\subsection{Electrochemical Characterization of the Aptamer-Modified Surface}

Cyclic voltammetric characterization of electroactive species is a valuable tool for testing the kinetic barrier and electrochemical exchange at the interface [38]. In this work, the different steps of the surface modification have been characterized using cyclic voltammetry where all experiments have been performed in the presence of the redox couples $\mathrm{K}_{3}\left[\mathrm{Fe}(\mathrm{CN})_{6}\right] / \mathrm{K}_{4}\left[\mathrm{Fe}(\mathrm{CN})_{6}\right]$ by scanning the potential between $-1 \mathrm{~V}$ and $1 \mathrm{~V}$, with a scan rate of $50 \mathrm{mV} \mathrm{s}^{-1}$. Figure 3 represents the electrochemical characterization of the bare and modified glassy carbon electrode by cyclic voltammetry. First, it can be seen from the voltammograms that the oxidation and reduction peaks of the redox couple are visible in the bare electrode, shown in curve a in Figure 3, due to the high exchange rate with the glassy carbon electrode. Then, after the modification of the electrode with CNTs/CS, shown in curve b in Figure 3), a voltametric effect of ferricyanide on the electrode was observed. Thiscan be explained by the active catalytic surface of carbon nanotubes which may increase the active surface of the modified electrode [39]. However, the oxidation and reduction peaks of the redox couple decreased, as compared to that observed with the 
bare GCE, due to the blocking behavior of CS [40]. After the electrodeposition of AuNPs (Curve $c$ in Figure 3) on the CNTs-CS/GCE surface, we noted that the oxydo/reduction peaks increased and the $\triangle \mathrm{Ep}$ decreased as compared to the CNTs/CS modified electrode. These results confirm the role of AuNPs in increasing the electroactive catalytic surface. We can see clearly that the highest peak was obtained with the AuNPs/CNT-CS composite, because of the large specific surface of the modified electrode and the synergistic effect of AuNPs and CNTs [41,42]. Finally, we can see from curve d in Figure 3, corresponding to the immobilization of the aptamer on the nanocomposite-modified GCE that the oxydo/reduction peaks, as well as the $\Delta \mathrm{Ep}$, have significantly decreased as compared to the AuNPs/CNTs-CS/GCE. This implies that most of the electrode surface was successfully covered with aptamer [43]. This decrease returns mainly to the negative charge of the phosphate backbone of the DNA aptamer acting as a barrier hindering the electron transfer. After incubating the aptasensing platform with a buffer solution $(\mathrm{pH}=4.5)$ containing $0.1 \mathrm{mM}$ cadmium $\mathrm{Cd}^{2+}$ during $30 \mathrm{mn}, \mathrm{CV}$ showed a further peak decrease and an increase in $\triangle \mathrm{Ep}$, in curve e in Figure 3. This behavior was attributed to the adsorption of $\mathrm{Cd}^{2+}$ on the surface, which considerably hampers the transfer of electrons between the surface of the electrode and the redox couples in solution due to the opening of the rod portion of aptamer and formation of the complex $\mathrm{Cd}^{2+}$-aptamer [44,45].

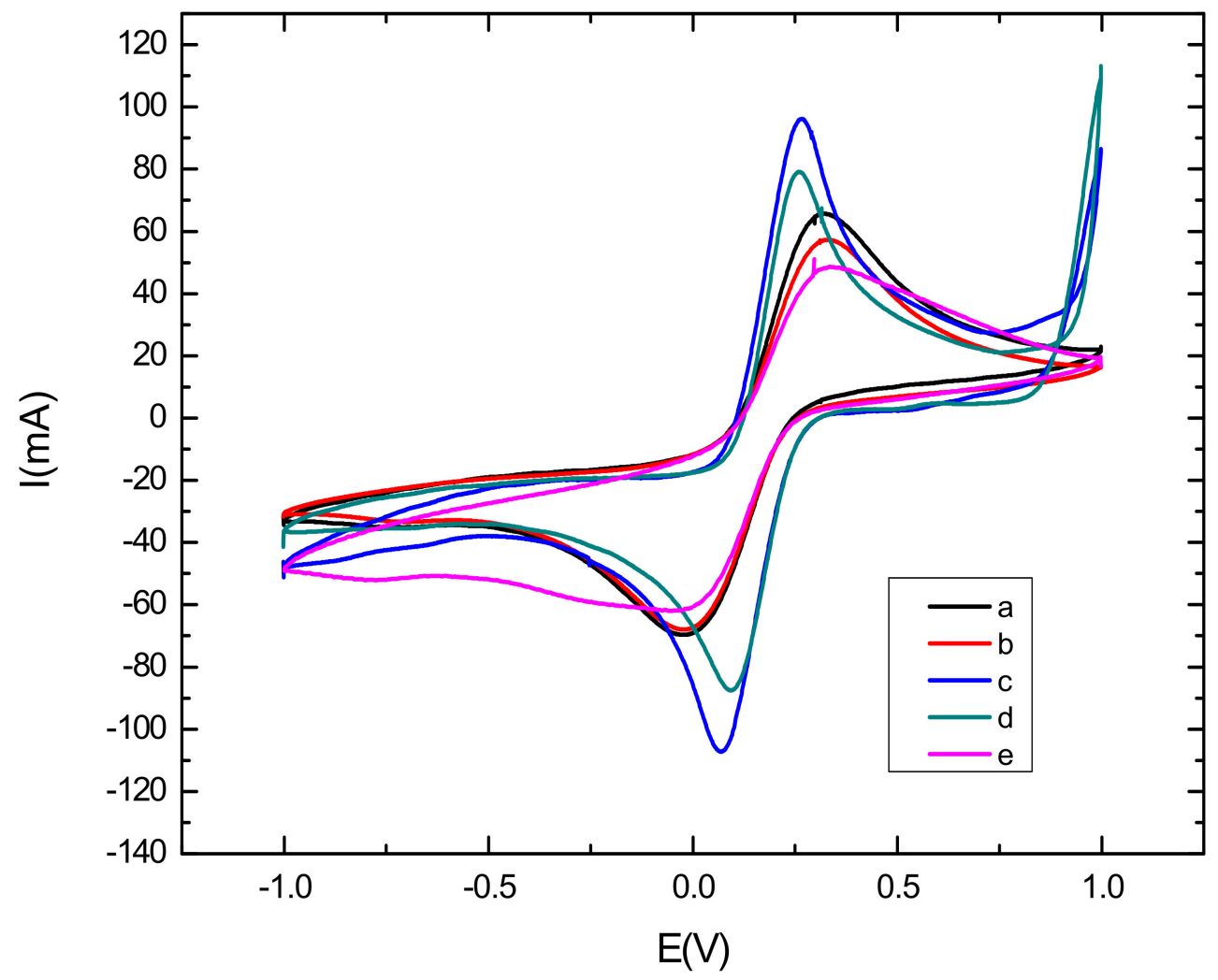

Figure 3. Cyclic voltammograms in the presence of $\mathrm{K}_{3}\left[\mathrm{Fe}(\mathrm{CN})_{6}\right] / \mathrm{K}_{4}\left[\mathrm{Fe}(\mathrm{CN})_{6}\right]$ for: bare electrode (curve a), Cs-CNTs/GCE (curve b), AuNPs/Cs-CNTs/GCE (curve c), Apta/AuNPs/Cs-CNTS/GCE (curve d), $\mathrm{Cd}^{2+} / \mathrm{Apta} / \mathrm{AuNPs} / \mathrm{Cs}-\mathrm{CNTS} / \mathrm{GCE}$ (curve e). Potential was scanned from $1 \mathrm{~V}$ to $-1 \mathrm{~V}$ with a scan rate of $50 \mathrm{mV} \mathrm{s}^{-1}$.

\subsection{Application of the Aptasensing Platform in the Impedimetric Detection of Cadmium}

The ability of the proposed aptasensor for the quantification of cadmium was evaluated. For that, the aptamer-modified surface was exposed to increasing concentrations of cadmium, under the optimal conditions. The experimental results showed a significant increase in the diameter of the Nyquist circle up on cadmium addition on the modified electrode surface. As can be seen from Figure 4A, the charge transfer resistance (Rct) values 
enhanced by increasing $\mathrm{Cd}^{2+}$ concentration in a logarithmic way. The first semi-circle of the Nyquist plot corresponds to the aptamer-modified surface before the addition of cadmium. After incubation with increasing concentrations of the target, the Nyquist plot semi-circles continue to increase, indicating the interaction between cadmium and its specific aptamer.
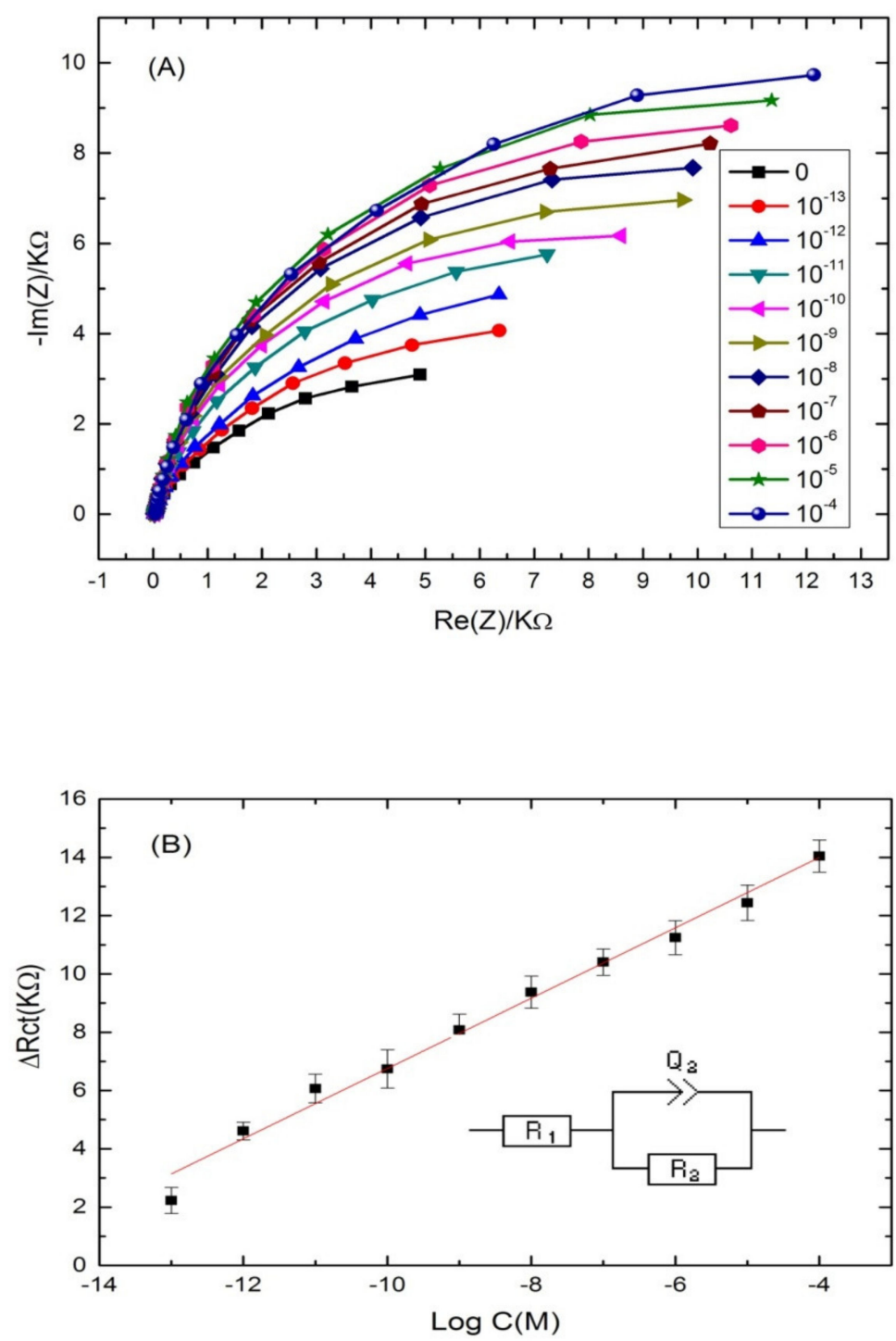

Figure 4. (A) Nyquist plots of Cd-aptamer-modified surface incubated with increasing concentrations of cadmium ranging from $10^{-4}$ to $10^{-13} \mathrm{M}$. Measurements were performed in buffer $(\mathrm{pH} 4.5)$ at a potential of $-0.5 \mathrm{~V}$ and a frequency range from $10 \mathrm{kHz}$ to $100 \mathrm{mHz}$. (B) Calibration plots of the increase of the charge transfer resistance with cadmium concentration for the label free aptasensor. Inset: equivalent circuit used for the EIS equivalent circuit fitting.

Nyquist plot semi circles were fitted using Randles equivalent circuit model (Figure 4B) where Rs represents the solution resistance, Rct represents the charge-transfer resistance and Q1 represents the constant phase element (an equivalent model of double-layer capacitance). The real part of impedance $(\operatorname{Re}(Z))$ increased as function of cadmium concentration. The results demonstrated that the more $\mathrm{Cd}^{2+}$ was bound on the aptasensing platform, the higher the Rct was. The linear regression equation was normalized to $\Delta$ Rct $=$ Rct (aptamer-cadmium) -Rct (aptamer) as a function logarithm of cadmium concentration. Rct (aptamer-cadmium) is the value of the electron transfer resistanceafter $\mathrm{Cd}^{2+}$ binding to the immobilized aptamer on the modified electrode surface. Rct (aptamer) represents the value of the electron transfer resistance after the aptamer immobilization on the modified 
electrode surface. A steady linear relationship between the Rct and cadmium concentrations was found in the range of concentrations $\left(10^{-13}-10^{-4} \mathrm{M}\right)$, with a good correlation coefficient of $\left(R^{2}=0.985\right)$ and a sensitivity of $1.2 \mathrm{~K} \Omega \cdot \mathrm{M}^{-1}$ per cadmium concentration decade. The limit of detection (LOD) of the aptasensor was $2.011 \times 10^{-14} \mathrm{M}$, calculated as the concentration of cadmium corresponding to the three times " $\mathrm{s} / \mathrm{m}$ " ratio, where " $\mathrm{s}$ " is the standard deviation of the blank impedance signal (three replicates) and " $\mathrm{m}$ " is the slope of the related calibration curve [46].

\subsection{Specificity and Reproducibility}

The specificity of the proposed aptasensor was evaluated by comparing the impedance changes after incubation with $\mathrm{Cd}^{2+}$ and other heavy metals, such as $\mathrm{Hg}^{2+}, \mathrm{Pb}^{2+}$ and $\mathrm{Zn}^{2+}$, during $30 \mathrm{~min}$. Three concentrations have been tested for each analyte; $10^{-8}, 10^{-7}$ and $10^{-6} \mathrm{M}$. At this stage, the interactivity of the biosensor and cadmium detection was performed only in PBS buffer. As can be observed in Figure 5, the impedance measurements show clearly that the biosensor was highly selective to cadmium as compared to the other tested heavy metals. No significant signals were recorded in the presence of $\mathrm{Pb}^{2+}$ and $\mathrm{Zn}^{2+}$. However, a slight cross-reactivity was noted with $\mathrm{Hg}^{2+}$ which may be attributed to the special T-Hg-T mismatched base pair between $\mathrm{Hg}^{2+}$ and Cd-aptamer [47-49]. These results show that the aptamer immobilized on the electrode surface maintains its affinity and specificity in reaction with the cadmium, producing a significant $\Delta$ Rct increase. This may be considered as a validation of the selectivity of the proposed aptasensor, because it allows the discrimination between the tested heavy metals into the entire selected range.

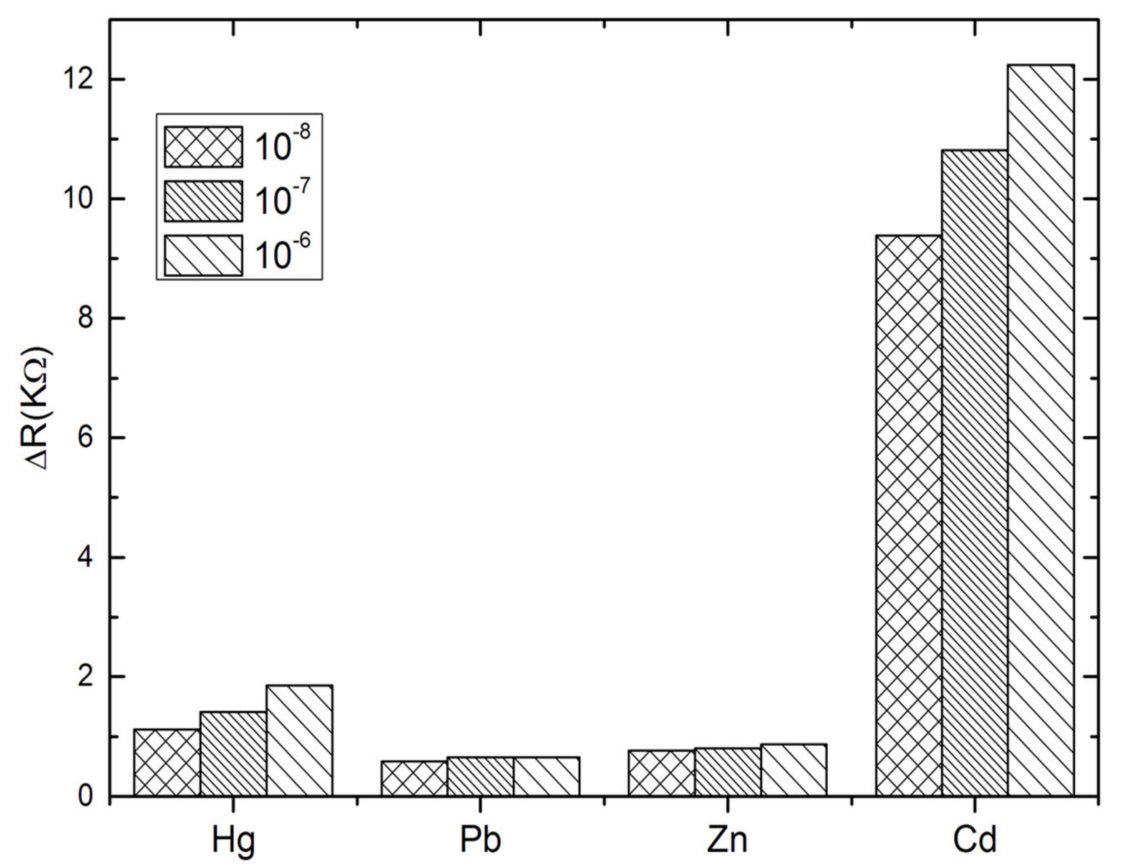

Figure 5. Selectivity studies of the aptasensor with mercury $\left(\mathrm{Hg}^{2+}\right)$, lead $\left(\mathrm{Pb}^{2+}\right)$ and $\mathrm{Zinc}\left(\mathrm{Zn}^{2+}\right)$.

The reproducibility of the developed aptasensing platform was tested with inter assay precision. The inter assay precision was evaluated by incubating three electrodes, independently prepared in the same experimental conditions with the same concentration of cadmium. The coefficient of variation obtained from three measurements was good, varying between $2 \%$ and $4 \%$ in the range of concentrations studied.

\subsection{Applicability in Real Water Samples}

The selective cadmium ion biosensor was used to test a water sample taken from Khenchela region, which represents an area of water contaminated with cadmium. The water sample was obtained from the Hammam Essalihine (Khenchela, east of Algeria). 
The initial concentration of cadmium ions was determined by atomic absorption spectroscopy (data not shown). Then, buffer dilutions ( $\mathrm{pH} 4.5)$ were prepared with these water samples. Afterwards, the sensor was subjected to different concentrations of cadmium prepared in water samples, and its response was revealed using the electrochemical impedance spectroscopy method. Figure 6A showsthe Nyquist plots corresponding to the aptamer-modified surface without cadmium addition, and after incubation with different concentrations of cadmium. A shift in the semi-circle with the first concentration $\left(10^{-8} \mathrm{M}\right)$ was observed, and attributed to the increase of resistance provided from an aptamer reaction with cadmium. The analysis of the other concentrations was performed in the same parameters. An increase in the semi-circular diameter was noted by increasing the cadmium concentration. The signal was improved and the analytical response of the biosensor was linear, within the range of $10^{-8}$ to $10^{-12} \mathrm{M}$ with a good correlation coefficient of $\left(\mathrm{R}^{2}=0.98\right)$ and a LOD of $10^{-12} \mathrm{M}$ (Figure $6 \mathrm{~B}$ ). These results confirm the feasibility of our label-free aptasensing strategy in real samples.
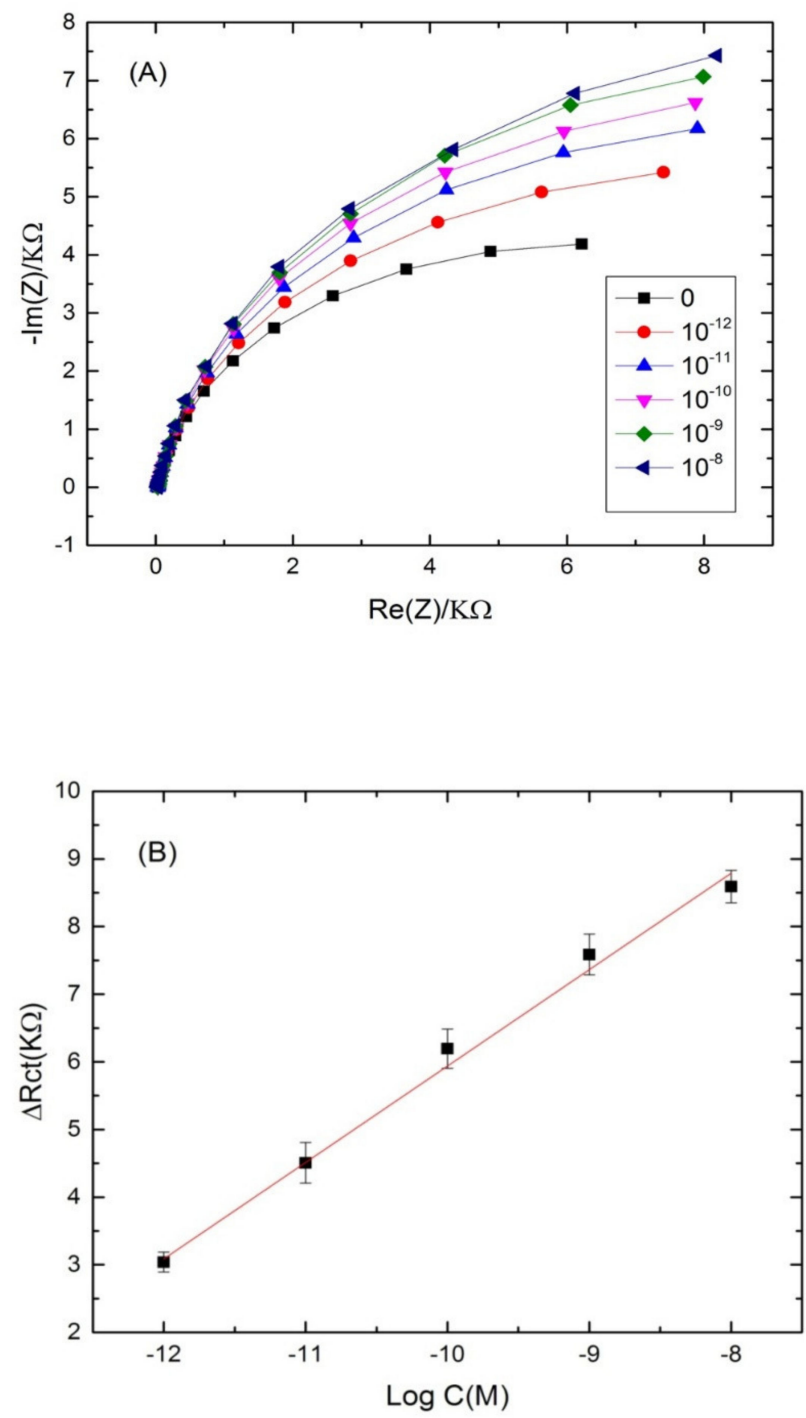

Figure 6. (A) Nyquist plots of Cd-aptamer-modified surface incubated with increasing concentrations of real samples spiked with cadmium. Measurements were performed at a potential of $-0.5 \mathrm{~V}$ and a frequency range from $10 \mathrm{kHz}$ to $100 \mathrm{mHz}$. (B) Calibration plots of the increase of the charge transfer resistance with cadmium concentration in real water samples for the label free aptasensor. 


\section{Conclusions}

In summary, a label-free aptasensor was successfully developed for cadmium determination in water samples. A new immobilization strategy was adopted in the construction of the sensing platform. For that, the aptamer was crosslinked on a glassy carbon electrode via a nanocomposite of carbon nanotubes, gold nanoparticles and chitosan. Due to the synergistic effect of CNTs and AuNPs, the as synthesized nanohybrid offered a biocompatible support for the DNA aptamer. In addition, it exhibited an excellent conductivity and electrocatalytic activity, thus enhancing the analytical performance. The label-free aptasensor has enabled the sensitive detection of cadmium with the detection limit of $0.02 \mathrm{pM}$. The obtained response was linear, in the range of $\left[10^{-13}-10^{-4} \mathrm{M}\right]$. Moreover, the aptasensor has shown a high selectivity to cadmium in the presence of other interfering metals, including $\mathrm{Hg}^{2+}, \mathrm{Pb}^{2+}$ and $\mathrm{Zn}^{2+}$. Finally, the constructed aptamer biosensor has been applied to detect cadmium in real samples with high accuracy. On the whole, this work opens a new avenue for aptamer immobilization on CNTs/AuNPs nanocomposites and their application in electrochemical biosensing.

Supplementary Materials: The following are available online at https:/ / www.mdpi.com/article/10 .3390 /s22010105/s1, Figure S1: Pictures of the real sensor and some fabrication steps.

Author Contributions: Methodology, S.R., A.T.; Funding acquisition, G.C.; Project administration, M.B.; Validation, J.-L.M.; Investigation, A.R.; Writing original draft, A.R. All authors have read and agreed to the published version of the manuscript.

Funding: This research received no external funding.

Institutional Review Board Statement: Not applicable.

Informed Consent Statement: Not applicable.

Data Availability Statement: Not applicable.

Conflicts of Interest: The authors declare no conflict of interest.

\section{References}

1. Sun, X.; Li, F.; Shen, G.; Huang, J.; Wang, X. Aptasensor based on the synergistic contributions of chitosan-gold nanoparticles, graphene-gold nanoparticles and multi-walled carbon nanotubes-cobalt phthalocyanine nanocomposites for kanamycin detection. Analyst 2014, 139, 299-308. [CrossRef] [PubMed]

2. Ku, T.-H.; Zhang, T.; Luo, H.; Yen, T.M.; Chen, P.-W.; Han, Y.; Lo, Y.-H. Nucleic acid aptamers: An emerging tool for biotechnology and biomedical sensing. Sensors 2015, 15, 16281-16313. [CrossRef] [PubMed]

3. Kumar Kulabhusan, P.; Hussain, B.; Yüce, M. Current perspectives on aptamers as diagnostic tools and therapeutic agents. Pharmaceutics 2020, 12, 646. [CrossRef] [PubMed]

4. Bognár, Z.; Gyurcsányi, R.E. Aptamers against immunoglobulins: Design, selection and bioanalytical applications. Int. J. Mol. Sci. 2020, 21, 5748. [CrossRef] [PubMed]

5. Liu, M.; Yin, Q.; Chang, Y.; Zhang, Q.; Brennan, J.D.; Li, Y. In vitro selection of circular DNA aptamers for biosensing applications. Angew. Chem. Int. Ed. 2019, 58, 8013-8017. [CrossRef]

6. Zhang, X.; Yadavalli, V.K. Surface immobilization of DNA aptamers for biosensing and protein interaction analysis. Biosens. Bioelectron. 2011, 26, 3142-3147. [CrossRef]

7. Wehbe, M.; Labib, M.; Muharemagic, D.; Zamay, A.S.; Berezovski, M.V. Switchable aptamers for biosensing and bioseparation of viruses (swaps-v). Biosens. Bioelectron. 2015, 67, 280-286. [CrossRef]

8. Urmann, K.; Modrejewski, J.; Scheper, T.; Walter, J.-G. Aptamer-modified nanomaterials: Principles and applications. BioNanoMaterials 2017, 18, 1-18. [CrossRef]

9. Nasrollahzadeh, M.; Sajadi, S.M.; Sajjadi, M.; Issaabadi, Z. Applications of nanotechnology in daily life. Interface Sci. Technol. 2019, 28, 113-143.

10. Altintas, Z. Biosensors and Nanotechnology: Applications in Health Care Diagnostics; John Wiley \& Sons: Hoboken, NJ, USA, 2017.

11. Lei, J.; Ju, H. Signal amplification using functional nanomaterials for biosensing. Chem. Soc. Rev. 2012, 41, 2122-2134. [CrossRef]

12. Putzbach, W.; Ronkainen, N.J. Immobilization techniques in the fabrication of nanomaterial-based electrochemical biosensors: A review. Sensors 2013, 13, 4811-4840. [CrossRef]

13. Guinovart, T.; Parrilla, M.; Crespo, G.A.; Rius, F.X.; Andrade, F.J. Potentiometric sensors using cotton yarns, carbon nanotubes and polymeric membranes. Analyst 2013, 138, 5208-5215. [CrossRef] 
14. Zhang, H.; Liu, G.; Chai, C. A novel amperometric sensor based on screen-printed electrode modified with multi-walled carbon nanotubes and molecularly imprinted membrane for rapid determination of ractopamine in pig urine. Sens. Actuators B Chem. 2012, 168, 103-110. [CrossRef]

15. Power, A.C.; Gorey, B.; Chandra, S.; Chapman, J. Carbon nanomaterials and their application to electrochemical sensors: A review. Nanotechnol. Rev. 2018, 7, 19-41. [CrossRef]

16. Soldano, C. Hybrid metal-based carbon nanotubes: Novel platform for multifunctional applications. Prog. Mater. Sci. 2015, 69, 183-212. [CrossRef]

17. Muhammad, A.; Yusof, N.A.; Hajian, R.; Abdullah, J. Construction of an electrochemical sensor based on carbon nanotubes/gold nanoparticles for trace determination of amoxicillin in bovine milk. Sensors 2016, 16, 56. [CrossRef]

18. Li, H.; Wang, W.; Lv, Q.; Xi, G.; Bai, H.; Zhang, Q. Disposable paper-based electrochemical sensor based on stacked gold nanoparticles supported carbon nanotubes for the determination of bisphenol a. Electrochem. Commun. 2016, 68, 104-107. [CrossRef]

19. Hamdy, M.E.; Del Carlo, M.; Hussein, H.A.; Salah, T.A.; El-Deeb, A.H.; Emara, M.M.; Pezzoni, G.; Compagnone, D. Development of gold nanoparticles biosensor for ultrasensitive diagnosis of foot and mouth disease virus. J. Nanobiotechnol. 2018, 16, 48. [CrossRef]

20. Jiang, P.; Wang, Y.; Zhao, L.; Ji, C.; Chen, D.; Nie, L. Applications of gold nanoparticles in non-optical biosensors. Nanomaterials 2018, 8, 977. [CrossRef]

21. Yuan, D.; Chen, S.; Yuan, R.; Zhang, J.; Liu, X. An ecl sensor for dopamine using reduced graphene oxide/multiwall carbon nanotubes/gold nanoparticles. Sens. Actuators B Chem. 2014, 191, 415-420. [CrossRef]

22. Cai, X.; Gao, X.; Wang, L.; Wu, Q.; Lin, X. A layer-by-layer assembled and carbon nanotubes/gold nanoparticles-based bienzyme biosensor for cholesterol detection. Sens. Actuators B Chem. 2013, 181, 575-583. [CrossRef]

23. Alim, S.; Vejayan, J.; Yusoff, M.M.; Kafi, A. Recent uses of carbon nanotubes \& gold nanoparticles in electrochemistry with application in biosensing: A review. Biosens. Bioelectron. 2018, 121, 125-136. [PubMed]

24. He, B.; Wang, L.; Dong, X.; Yan, X.; Li, M.; Yan, S.; Yan, D. Aptamer-based thin film gold electrode modified with gold nanoparticles and carboxylated multi-walled carbon nanotubes for detecting oxytetracycline in chicken samples. Food Chem. 2019, 300, 125179. [CrossRef] [PubMed]

25. Tsai, Y.-C.; Chen, S.-Y.; Liaw, H.-W. Immobilization of lactate dehydrogenase within multiwalled carbon nanotube-chitosan nanocomposite for application to lactate biosensors. Sens. Actuators B Chem. 2007, 125, 474-481. [CrossRef]

26. Kang, X.; Mai, Z.; Zou, X.; Cai, P.; Mo, J. A novel glucose biosensor based on immobilization of glucose oxidase in chitosan on a glassy carbon electrode modified with gold-platinum alloy nanoparticles/multiwall carbon nanotubes. Anal. Biochem. 2007, 369, 71-79. [CrossRef]

27. Turner, A. Cadmium pigments in consumer products and their health risks. Sci. Total Environ. 2019, 657, 1409-1418. [CrossRef]

28. World Health Organization. Guidelines for drinking-water quality. WHO Chron. 2011, 38, 104-108.

29. Rabai, S.; Benounis, M.; Catanante, G.; Baraket, A.; Errachid, A.; Renault, N.J.; Marty, J.-L.; Rhouati, A. Development of a label-free electrochemical aptasensor based on diazonium electrodeposition: Application to cadmium detection in water. Anal. Biochem. 2021, 612, 113956. [CrossRef]

30. Wu, Y.; Zhan, S.; Wang, L.; Zhou, P. Selection of a DNA aptamer for cadmium detection based on cationic polymer mediated aggregation of gold nanoparticles. Analyst 2014, 139, 1550-1561. [CrossRef]

31. Araar, H.; Benounis, M.; Direm, A.; Touati, A.; Atailia, S.; Barhoumi, H.; Jaffrezic-Renault, N. A new thin film modified glassy carbon electrode based on melaminium chloride pentachlorocuprate (ii) for selective determination of nitrate in water. Mon. Chem.-Chem. Mon. 2019, 150, 1737-1744. [CrossRef]

32. He, B.-S.; Yan, S.-s. Electrochemical aptasensor based on aptamer-complimentary strand conjugate and thionine for sensitive detection of tetracycline with multi-walled carbon nanotubes and gold nanoparticles amplification. Anal. Methods 2018, 10, 783-790. [CrossRef]

33. Azadbakht, A.; Roushani, M.; Abbasi, A.R.; Derikvand, Z. A novel impedimetric aptasensor, based on functionalized carbon nanotubes and prussian blue as labels. Anal. Biochem. 2016, 512, 58-69. [CrossRef]

34. Saeedfar, K.; Heng, L.Y.; Chiang, C.P. A DNA biosensor based on gold nanoparticle decorated on carboxylated multi-walled carbon nanotubes for gender determination of arowana fish. Bioelectrochemistry 2017, 118, 106-113. [CrossRef]

35. Wang, Y.; Iqbal, Z.; Mitra, S. Microwave-induced rapid chemical functionalization of single-walled carbon nanotubes. Carbon 2005, 43, 1015-1020. [CrossRef]

36. Molaei, R.; Sabzi, R.E.; Farhadi, K.; Kheiri, F.; Forough, M. Amperometric biosensor for cholesterol based on novel nanocomposite array gold nanoparticles/acetone-extracted propolis/multiwall carbon nanotubes/gold. Micro Nano Lett. 2014, 9, 100-104. [CrossRef]

37. Tlili, A.; Abdelghani, A.; Hleli, S.; Maaref, M.A. Electrical characterization of a thiol sam on gold as a first step for the fabrication of immunosensors based on a quartz crystal microbalance. Sensors 2004, 4, 105-114. [CrossRef]

38. Elgrishi, N.; Rountree, K.J.; McCarthy, B.D.; Rountree, E.S.; Eisenhart, T.T.; Dempsey, J.L. A practical beginner's guide to cyclic voltammetry. J. Chem. Educ. 2018, 95, 197-206. [CrossRef]

39. Salinas-Torres, D.; Huerta, F.; Montilla, F.; Morallón, E. Study on electroactive and electrocatalytic surfaces of single walled carbon nanotube-modified electrodes. Electrochim. Acta 2011, 56, 2464-2470. [CrossRef] 
40. Wei, X.; Xu, X.; Qi, W.; Wu, Y.; Wang, L. Molecularly imprinted polymer/graphene oxide modified glassy carbon electrode for selective detection of sulfanilamide. Prog. Nat. Sci. Mater. Int. 2017, 27, 374-379. [CrossRef]

41. Feng, Y.; Wei, Z.; Zhang, J. Determination of ursolic acid in extracts from ligustri lucidum fruit using an electrochemical method. Front. Chem. 2020, 8, 444. [CrossRef]

42. Anupriya, J.; Babulal, S.M.; Chen, T.-W.; Chen, S.-M.; Kumar, J.V.; Lee, J.-W.; Rwei, S.-P.; Yu, J.; Yu, R.; Hong, C.-Y. Facile hydrothermal synthesis of cubic zinc ferrite nanoparticles for electrochemical detection of anti-inflammatory drug nimesulide in biological and pharmaceutical sample. Int. J. Electrochem. Sci. 2021, 16, 1-19. [CrossRef]

43. Hashkavayi, A.B.; Raoof, J.B.; Azimi, R.; Ojani, R. Label-free and sensitive aptasensor based on dendritic gold nanostructures on functionalized sba-15 for determination of chloramphenicol. Anal. Bioanal. Chem. 2016, 408, 2557-2565. [CrossRef]

44. Luan, Y.; Lu, A.; Chen, J.; Fu, H.; Xu, L. A label-free aptamer-based fluorescent assay for cadmium detection. Appl. Sci. 2016, 6, 432. [CrossRef]

45. Bagheryan, Z.; Raoof, J.-B.; Golabi, M.; Turner, A.P.; Beni, V. Diazonium-based impedimetric aptasensor for the rapid label-free detection of salmonella typhimurium in food sample. Biosens. Bioelectron. 2016, 80, 566-573. [CrossRef] [PubMed]

46. Riley, C.M.; Rosanske, T.W. Development and Validation of Analytical Methods; Elsevier: New York, NY, USA, 1996.

47. Chiang, C.-K.; Huang, C.-C.; Liu, C.-W.; Chang, H.-T. Oligonucleotide-based fluorescence probe for sensitive and selective detection of mercury (ii) in aqueous solution. Anal. Chem. 2008, 80, 3716-3721. [CrossRef] [PubMed]

48. Gao, C.; Wang, Q.; Gao, F.; Gao, F. A high-performance aptasensor for mercury (ii) based on the formation of a unique ternary structure of aptamer-hg 2+-neutral red. Chem. Commun. 2014, 50, 9397-9400. [CrossRef] [PubMed]

49. Tang, C.-X.; Zhao, Y.; He, X.-W.; Yin, X.-B. A "turn-on" electrochemiluminescent biosensor for detecting hg2+ at femtomole level based on the intercalation of ru (phen) 32+ into ds-DNA. Chem. Commun. 2010, 46, 9022-9024. [CrossRef] 